\title{
PREPARATION AND CHARACTERIZATION OF ACTIVATED CARBON FROM AGRICULTURAL WASTEBY MICROWAVE IRRADIATION
}

\author{
Hossam Altaher ${ }^{1,2}$, Manar Hassan ${ }^{3}$, Fahd ElOufi $^{1}$, Yehia Magdy ${ }^{4}$ \\ ${ }^{1}$ Department of Chemical Engineering Technology, Yanbu Industrial College, Saudi Arabia \\ ${ }^{2}$ University of Nizwa, Birkat ElMouz, , Sultanate of Oman \\ ${ }^{3}$ National Institute of Laser Enhanced Science (NILES), Cairo University, Egypt \\ ${ }^{4}$ Chemical Engineering Department, Faculty of Engineering, Minia University, Egypt \\ Email: haltaher@hotmail.com
}

\begin{abstract}
In this study, activated carbon was prepared by microwave radiation from dates pits using three chemical activators namely, zinc chloride, phosphoric acid and sulfuric acid. Different preparation conditions like activator type, power and time of microwave radiation were assessed. The efficiency of prepared activated carbon was evaluated by adsorption of methylene blue. The prepared activated carbon was characterized by scanning electron microscope (SEM), Fourier Transform IR (FTIR), X-ray diffraction analysis (XRD) and elemental analysis. The pore size distribution and the surface area were also determined. Based on the results, the optimum conditions for AC preparation were high power of microwave, and activation for 12 minutes of radiation with zinc chloride as the chemical activator. Under these conditions, the adsorption capacity of MB was $61 \mathrm{mg} / \mathrm{g}$. The activation process has enhanced to a great extent the surface of the precursor by increasing its porosity and its surface area. Most of the pores formed on the surface were macropores which work as conduits to meso and micropores.
\end{abstract}

Keywords: Activated carbon, adsorption, characterization, microwave, pyrolysis, structure

\section{INTRODUCTION}

Due to large surface area and large pore volume, porous activated carbons have been employed in a wide number of applications such as purification of gases, water and wastewater treatment and catalytic processes. In spite of its effectiveness in all above mentioned processes, the high cost of activated carbon production, consequently its high price, has restricted its widespread use. This fact has prompted a growing interest in investigating for new techniques to reduce the cost of production. The high cost of production of $\mathrm{AC}$ is due to the following reasons. The thermal treatment is the regular method for production of activated carbon. It uses high temperature $\left(700-1000^{\circ} \mathrm{C}\right)$ to convert the precursor to AC. The long thermal processing, which means high cost of energy, together with the large space for equipment also increase the cost of production [7]. On the other hand, microwave heating for manufacturing of activated carbon has very important advantage which is considerable decrease in the treatment time. This represents a reduction in the energy consumption. Microwave heating method also has the advantages of a controllable heating process, indirect contact 
between the microwave radiation source and the materials, smaller equipment and the generation of less waste [35]. Microwave energy is derived from electrical energy. The conversion efficiency of precursor to $\mathrm{AC}$ is approximately $50 \%$ for $2450 \mathrm{MHz}$ and $85 \%$ for $915 \mathrm{MHz}$. In addition, using microwave energy may reduce the consumption of gases used in the thermal treatment [30]. Porosity and surface area play an important role in determining the properties and adsorption capacity of activated carbon. Textural property of activated carbon relies on activation conditions (activation agent, temperature and time) and type of precursor. The surface chemical functional groups are mainly due to activation process, heat treatment and post chemical treatment, method of preparation and raw material [21], [25]. The quality and yield of activated carbon may be affected by carbonization temperature, carbonization heating rate, the carbonization residence time and the nitrogen flow rate. In addition, the non-uniform distribution of the heat and the surface heating of the precursor may produce a poor quality activated carbon [18]. To conquer the above mentioned problems, microwave heating is proposed rather than conventional activated carbon preparation technique. A microwave oven works by passing nonionizing microwave radiation, usually at a frequency of $2.45 \mathrm{GHz}$ through the substance. Microwave energy is readily transformed inside the particles by dipole rotation and ionic conduction while in conventional heating energy is transferred by conduction or convection [3], [6].The material is penetrated by microwave energy through interaction of the electromagnetic field at the molecular level. The effect of the electromagnetic field on the material is determined by dielectric properties [29].
The dielectric material interaction with microwaves causes translational motions of free or bound charges and rotation of the dipoles. The resistance of these persuaded motions because of inertial, elastic, and frictional forces causes losses in volumetric heating [26]. This makes microwave a perfect solution for providing uniform distribution of the heat internally and externally. The electrical consumption was also found to be less compared to conventional technique [7]. Shape, size, dielectric constant of material and the nature of the microwave equipment used are factors that affect the way in which a material will be heated by microwaves. The mechanism of heating of the material using microwave radiation might be as follows [14], [17]:

1. Dipole reorientation: when substances containing polar compounds are exposed to a microwave field, the electrons around the nuclei or the atomic nuclei themselves are shifted from their stability position, forming induced dipoles. In the fluctuating field, the chemicals bonds are rearranged. This rearrangement results in friction between the revolving molecules, and heat to be produced within the entire volume of material.

2. Interfacial polarization: It occurs from a charge build-up in the contact areas. The build up of space charge initiates field deformations and dielectric loss that contribute to the heating effects.

3. Conduction mechanism: The electric currents are produced when an electrically-conductive material is subjected to electromagnetic radiation.

Shortly after commencement of radiation, the maximum temperature is near the surface. As time increases, the position of maximum temperature moves into the interior of the object. The profile that is established will 
depend on the power, the electric field, the dielectric and thermal properties of the body [28]. In this study, attempts were made to prepare activated carbon through microwave carbonization using various chemical activators. Taking advantage of the abundance of dates pits as an agricultural waste in Saudi Arabia, this material was used as precursor. A further aim was to explore the effect of microwave heating on the textural and surface chemical properties of activated carbon. The properties of the prepared activated carbon compared to the precursor were also studied.

\section{MATERIALS AND METHODS}

\subsection{EQUIPMENT}

The Scanning Electron Microscope (SEM) images were carried out using SEM Model Philips XL 30 (Netherlands) attached with EDX Unit, with accelerating voltage $30 \mathrm{~K} . \mathrm{V}$., magnification $10 \mathrm{x}$ up to $400.000 \mathrm{x}$ and resolution for W $(3.5 \mathrm{~nm})$. Samples are coated with gold. Elemental analysis of the samples was performed using "Elemental CHNS analyser Vario EL III Germany”. Pore size distribution and surface area determination of the adsorbents were tested using NOVA Surface Area Analyzer from Quantachrome Instruments (Nova 2000 series USA). The determination of the functional groups on the surface was performed using FT-IR 4100 Jasco, Japan.

\subsection{PREPARATION OF ACTIVATED CARBON}

The dates pits (DP) were obtained from a processing and packing plant of dates in Madinah, Saudi Arabia. The pits were washed exhaustively with tap water, followed by washing with distilled water for three times to remove dust and foreign material.
The pits were then dried overnight at $105^{\circ} \mathrm{C}$, crushed and sieved into a uniform size of less than $1.0 \mathrm{~mm}$. The crushed pieces were mixed with the chemical activator (zinc chloride) at a mass ratio of 1:1. Distilled water was added and the mixture was agitated overnight to reach homogeneity. The impregnated precursor was divided into two parts. The first part was heated in muffle furnace at $500^{\circ} \mathrm{C}$ for two hours under nitrogen flow at heating rate of $10 \mathrm{~K} / \mathrm{min}$. The product was washed several times with distilled water until the $\mathrm{pH}$ of the washing water reached 6.0-7.0. The product was dried at $105^{\circ} \mathrm{C}$, crushed and sieved into uniform size and kept in stoppered glass bottles for further use. The second portion of the mixture of dates pits and activator was carbonized using a microwave oven. Microwave carbonization was carried out in a $2.45 \mathrm{GHz}$ commercial microwave oven with suitable modifications. The oven has a power controller to select from different power levels $(\mathrm{MH}=$ medium high energy, $\mathrm{ML}=$ medium low energy, $\mathrm{H}=$ high energy, $\mathrm{M}=$ medium energy) and a timer for various exposure times (7 to $18 \mathrm{mins}$ ). The carbonization was carried out in quartz crucibles placed on the turning plate contained in the chamber of the microwave oven. Nitrogen gas at a pre-set flow rate was used to purge any air in the chamber (for 12 minutes) before the start of the microwave irradiation process and it continued to flow through the chamber during the whole process. The flow of nitrogen was continued during the cooling stage (10minutes). The product was washed with the same procedure applied for thermal process. 


\subsection{METHYLENE ADSORPTION}

BLUE

(MB)

The comparison was undertaken in a series of 150-mL Erlenmeyer flasks containing 0.12g (weighed to the fourth decimal point) adsorbent and $50 \mathrm{~mL}$ of dye solution with initial concentrations of $50 \mathrm{mg} / \mathrm{L}$. The flasks were agitated at room temperature for 4 hours at a constant agitation rate of $300 \mathrm{rpm}$. The final concentration of dye was determined using UV-VIS spectrophotometer (UV mini1240, Shimadzu).

\section{RESULTS AND DISCUSSION}

The preliminary experiments indicated that the optimum activated carbon was prepared with high microwave power, activation time of $12 \mathrm{~min}$, and with zinc chloride as a chemical activator. All the characterization experiments were conducted for the previously mentioned sample.

\subsection{FOURIER TRANSFORMS INFRARED SPECTROSCOPY (FTIR) SPECTROSCOPY}

Besides porosity, adsorption behavior of activated carbon is influenced by the chemical reactivity of the surface especially in the form of chemisorbed oxygen in various forms of functional groups. FTIR was carried out on samples of dates pits, activated carbon (high microwave power, $12 \mathrm{~min}$ activation time, $\mathrm{ZnCl}_{2}$ activator, Shortly $\mathrm{H}, \mathrm{Z}, 12$ ), and activated carbon loaded with methylene blue. FT-IR spectrum of $\mathrm{MB}$ is characterized by aromatic ring at 1603 and $1394 \mathrm{~cm}^{-1}$. Figure 1 and Table 1 shows the large difference between the surface of the precursor and the activated carbon and activated carbon loaded with MB. While the precursor surface is rich with many functional groups the activated carbon has lost many of these functional groups or at least the intensity of peaks has been decreased. The bands on the surface of dates pits are introduced in Table 1. From the activated carbon spectrum, as illustrated by Table 1, fewer functional groups were detected, indicating that the surface functional groups of dates pits have experienced chemical changes during pyrolysis. The main peaks that disappeared are the peaks at $1740.44,1378.85,1315.21,1248.68$, 1075.12, 942.056, 874.56, 807.063, 605.539, representing Carboxylate $\mathrm{C}=\mathrm{O}$ Stretching, In plane bending vibration of $\mathrm{C}-\mathrm{H}$ of methylene group and methyl group, $\mathrm{C}-\mathrm{O}$ stretching vibrations in carboxylate groups, $\mathrm{C}-\mathrm{O}$ stretching vibrations in alcohols, phenols, or ether or ester groups, $\mathrm{C}-\mathrm{OH}$ stretching Vibrations, out of plane $\mathrm{OH}$ bending in carboxylic acid dimmers at 937-913, C-H out of plane in -CHO aldehydes, out-of-plane bending mode of $\mathrm{O}-\mathrm{H}, \mathrm{O}-\mathrm{H}$ out-of-plane bending vibrations band, respectively. Many other bands decrease dramatically indicating the decrease in functionality in the main matrix. The results of FTIR analysis indicated that a large number of carbonyl and hydroxyl groups were included on the surface of the material, and these groups could be the potential active sites for interaction with the cationic dye.

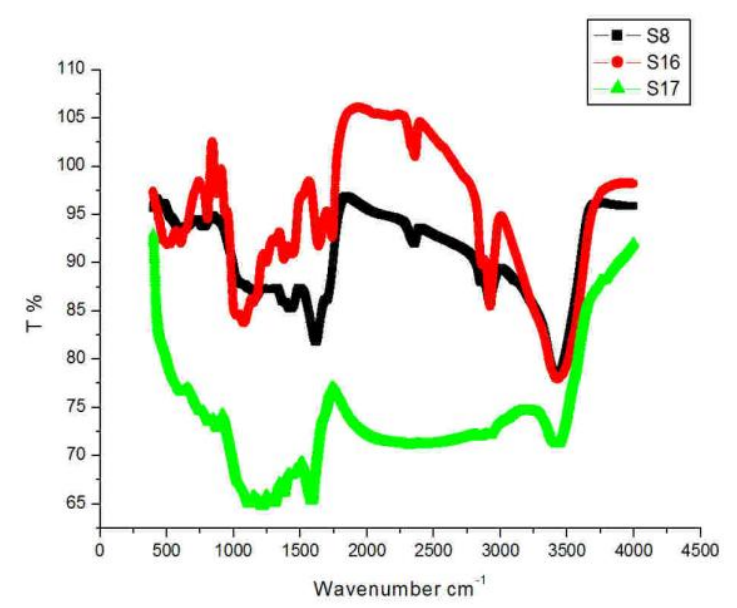

Fig. 1. FTIR spectrum of dates pits (S16), activated carbon (S8) and activated carbon after adsorption of $\mathrm{MB}(\mathrm{S} 17)$ 


\subsection{CHNS}

Table 2 shows an elemental analysis of the precursor and prepared activated carbon. The high nitrogen content in the precursor may be converted into functional groups containing donor nitrogen atoms during activation and thus may be functioning more effectively in removing and interacting with many adsorbates of acidic nature. While the porosity of activated carbon is the key player when absorbing gases and vapors, the chemical nature of their surface plays a significant role in liquid phase interactions. Due to the lone pair of electron on the nitrogen atoms, the $\mathrm{AC}$ containing various nitrogen groups, present more basic character and increased adsorption of acidic agents is expected [36]. The precursor contains also a higher content of volatile matter (hydrogen) and oxygen suitableto develop porosity and surface acidic groups containing oxygen depending onactivation process. The hydrogen content decreased from 7.01\% forprecursor to $3.83 \%$, while nitrogen content increased from 1.37 to $1.63 \%$. The carbon content increased from 45.08 to $52.97 \%$. The precursor did not contain sulfur. Determination of percentage of oxygen was calculated by difference. It can be concluded from the table that the majority of mass loss in the carbonization step is due to the loss of volatile components in the precursor such as hydrogen and oxygen which lead to the production of carbonaceous material. The increase in mass of nitrogen is probably due to the nitrogen purge.

\subsection{SEM ANALYSIS}

To study the effect of activation and carbonization process on the surface morphology of prepared activated carbon, SEM study was carried out for raw dates pits and prepared activated carbon at different magnifications. As can be noticed from Figures 2(a) and 2(b) the raw DP surface shows relatively irregular regions. No cracks or pores can be observed on the surface. However, some bumps can be identified all over the surface. The pores present on the surface, if any, have very large dimensions. According to the International Union of Pure and Applied Chemistry (IUPAC), pores can be classified into three categories according to the diameter of the pore. The first category has an average diameter of less than $2 \mathrm{~nm}$. Such pores are called micropores. Pores having diameter in the range $2-50 \mathrm{~nm}$ are called mesopores. Pores of diameter greater than $50 \mathrm{~nm}$ are called macropores.

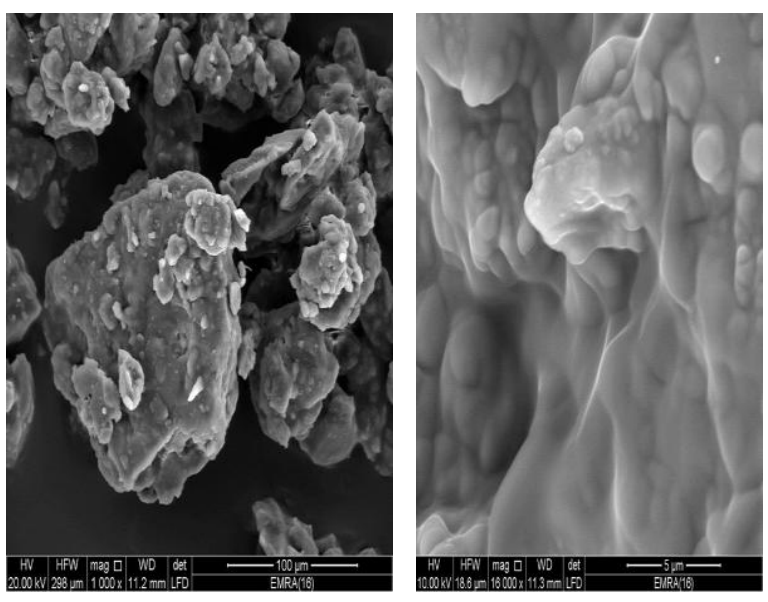

Fig. 2(a). SEM images of raw dates pits
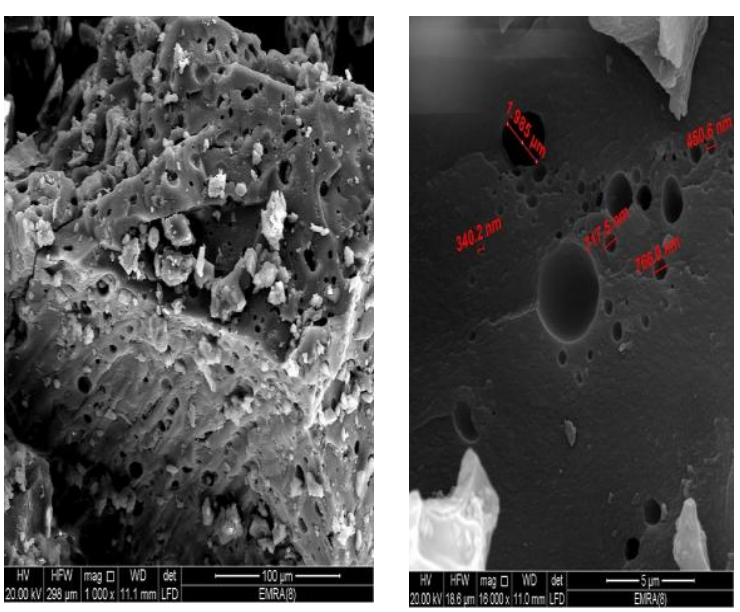

Fig. 2(b). SEM images of activated carbon 
The pores on the surface of prepared activated carbon are circular in shape without considerable deformation. However, their distribution on the surface is not homogeneous. The size of the pores is not identical either. The large pores may be due to the combination of some adjacent pores after the lateral walls have fallen on each other as a result of the thermal treatment. It can be noticed from Figure 2 that a considerable part of the surface of the activated carbon does not contain any pores which indicates that the activation process is not complete. However, further increase in activation time has led to decrease in the yield of activated carbon. It can be noticed that most pores are macropores and expose the surface. These macropores work as conduits to meso and micropores [11] as illustrated by Figure 3 .

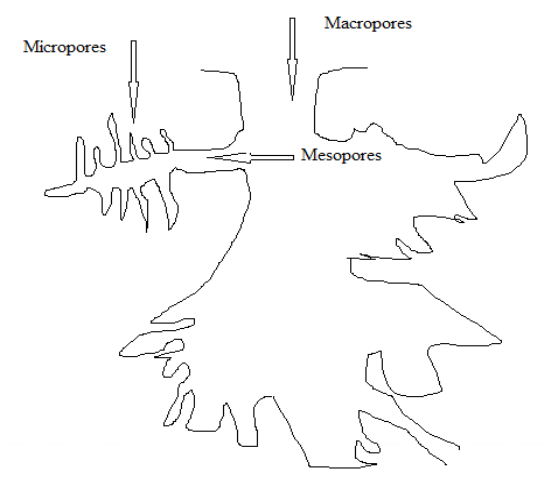

Fig. 3. Pore distribution on surface of activated carbon

These large pores (macropores) are formed due to the high corrosive and dehydrating action of the used chemical activator $\left(\mathrm{ZnCl}_{2}\right)$. During the activation process, the lateral bonds between precursor molecules break down which results in increasing the interand intra-micelle voids. The hydration causes the organic matter to decompose causing the formation of porous structure [20].

\subsection{PORE SIZE DISTRIBUTION AND SURFACE AREA}

According to the International Union of Pure and Applied Chemistry (IUPAC), pores can be classified into three categories according to the diameter of the pore. The first category has an average diameter of less than $2 \mathrm{~nm}$. Such pores are called micropores. Pores having diameter in the range $2-50 \mathrm{~nm}$ are called mesopores. Pores of diameter greater than $50 \mathrm{~nm}$ are called macropores. Table 3 shows the surface area and pore size calculation from nitrogen adsorption. BET surface area calculations were performed at 0.1 relative pressures in order to make the results physically meaningful, a common procedure for microporous materials. It is clear that the surface area increased by $70 \%$ compared with the precursor (DP). This increase of surface area is attributed to the formation of pores on the surface of AC. The pore volume also received an increase of $35 \%$. This increase is attributed to dehydrating action of the activator (zinc chloride) and to the removal of the volatile elements such as hydrogen and oxygen which leave vacant pores on the surface when volatilized.

\subsection{EFFECT OF PREPARATION CONDITIONS ON ADSORPTION EFFICIENCY}

\subsubsection{Effect of activation time}

Figure 4 shows the effect of activation time on the adsorption uptake (qe) of methylene blue. It is evident that increasing the radiation time caused increase in the adsorption uptake. 
The increase of activation time from 7 minutes to 18 minutes resulted in increase of uptake from 5.5 to $80 \mathrm{mg} / \mathrm{g}$. The prolonged exposure of precursor to microwave radiation would lead to form more pores on the surface. In the microwave activation, the mechanism for dielectric heating is dipolar loss, also known as the re-orientation loss mechanism. When a material containing permanent dipoles is subject to a varying electromagnetic field, the dipoles are unable to follow the rapid reversals in the field. As a result of this phase lag; power is dissipated in the material [14]. As the power is increasing the dissipated energy increases producing more heating effect. Through conduction in the object, heat will be transferred towards the centre of the object. The net result of these two effects is a temperature profile that varies with time. Shortly after commencement of radiation, the maximum temperature is near the surface. As time increases, the position of maximum temperature moves into the interior of the object [28]. So, the prolonged exposure of precursor to microwave radiation would lead to form more pores on the surface [18]. The maximum adsorption capacity for methylene blue increased with increase of time. The maximum value was obtained after $30 \mathrm{~min}$. The results indicated that the increase of microwave radiation time increased the pore volume of activated carbon. One very important thing to take into consideration is the relation between the activation time and the AC yield (results are not presented). Increasing the activation time will increase the AC yield up to a certain point (12 minutes in this research). After that the yield will decrease again due to the ashing of some of the produced AC.

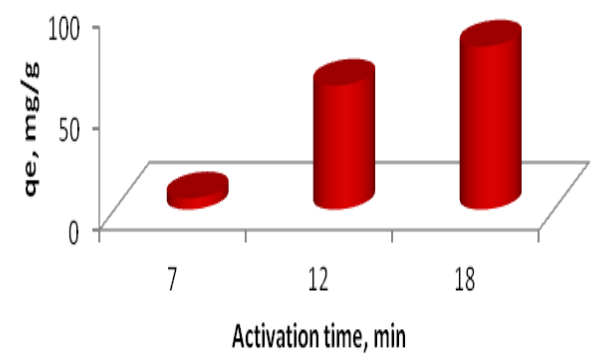

Fig. 4. Effect of activation time on adsorption capacity of $M B$ on AC prepared by microwave

\subsubsection{Effect of microwavepower}

Accurate prediction of process energy consumption from laboratory scale microwave testing is difficult for many reasons. These include; surface to volume ratio and heat loss effects, difficulties in calibration of power sensors, non-optimal applicator designs with high reflected powers, large wall losses, especially in stainless steel cavities, and uncertainty in predicting magnetron efficiencies at high powers. However the power scale of microwave used was divided into 4 parts, everyone indicating a certain energy level. The uptake of methylene blue onto the prepared activated carbons at different energy levels is shown in Figure 5. It can be seen that the amount of methylene blue adsorbed per unit mass of adsorbent increased with increasing irradiation power. At the low and medium microwave power the adsorption capacity was low but increasing the microwave power to the medium high and high ranges resulted in drastic increase in the adsorption capacity. This can be attributed to insufficient formation of the pores at the low energy levels. This result indicated that the increase of radiation energy of microwave had a pronounced effect on the porosity of the activated carbon [11]. 
Increasing the activation energy increased the porosity and decreased the apparent density. On the other hand, [5] found that the increase of radiation energy increased the adsorption capacity of methylene blue up to a certain energy value, after that the adsorption capacity decreased again. They attributed this to the destruction of some pores at the higher energy of radiation.

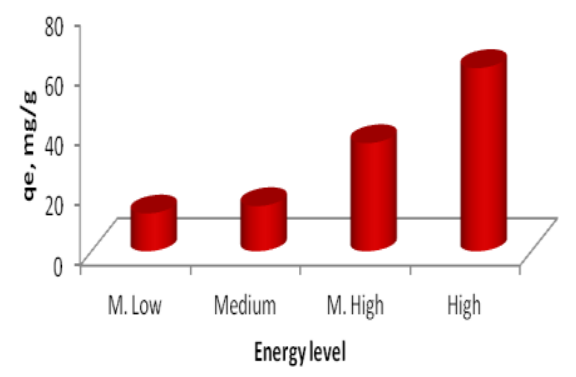

Fig. 5. Effect of activation energy on adsorption capacity of $M B$ on $\mathrm{AC}$

\subsubsection{Effect of type of chemical activator}

The adsorption capacity of activated carbon depends not only on its surface area, but also on its internal pore structure, surface characteristic and the functional group present on the pore surface. These properties are decided by the precursor, the chemical activator and preparation conditions [9, 23]. The activating agents influence the pyrolytic process and decrease the tar formation which enhances the yield of carbon. Another advantage of chemical activation is the reduction of activation temperature and activation time compared to the physical activation processes [8], and enhancing the pore development in the carbon structure [13,15]. Furthermore, activated carbon obtained by chemical activation is mesoporous with a larger surface area which enhances the removal of large size molecules [8].
The disadvantages of the chemical activation are the consumption of relatively expensive activating agents and the problems related to the washing and re-utilization of these agents [8]. Figure 6 indicates that at the preparation conditions, $\mathrm{AC}$ prepared using $\mathrm{ZnCl}_{2}$ as an activating agent gave the best adsorption capacity compared to activated carbon prepared using other activators $\left(\mathrm{H}_{2} \mathrm{SO}_{4}\right.$ and $\left.\mathrm{H}_{3} \mathrm{PO}_{4}\right)$. These results may be attributed to the ability of acids to bond cleavage leading to the formation of cross-linked structure, whereas $\mathrm{ZnCl}_{2}$ can diffuse and intercalate into the carbon lamellae to induce the separation of layer and pore development. That means the nature of the activator will play different roles on structure development of the raw precursor [13]. Investigating the figure will indicate that the precursor, when treated with different activators, are sensitive to time of activation with different degrees. Increasing time of activation from 7 to 12 minutes increased the percentage of dye uptake by 12 , 45, $6.5 \%$ for $\mathrm{H}_{3} \mathrm{PO}_{4}, \mathrm{H}_{3} \mathrm{PO}_{4}$ and $\mathrm{ZnCl}_{2}$, respectively. The response to energy of activation followed the same trend with $\mathrm{ZnCl}_{2}$ to respond more effectively (22\%) than $\mathrm{H}_{3} \mathrm{PO}_{4}(11.4 \%)$ and $\mathrm{H}_{3} \mathrm{PO}_{4}(6.6 \%)$.

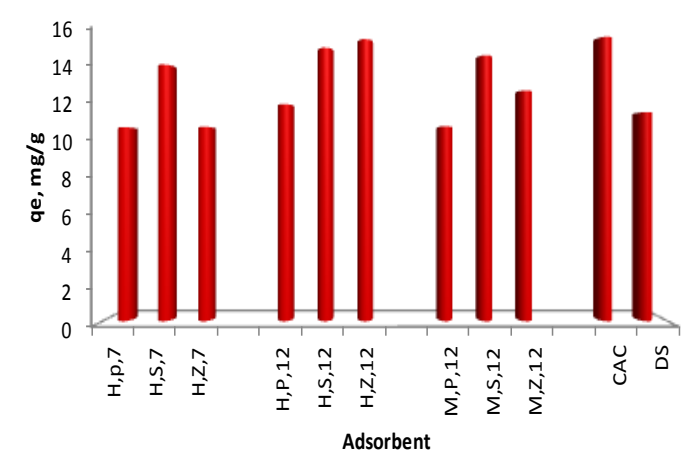

Fig. 6. Performance of different adsorbents prepared at different conditions in removal of methylene blue; $\mathrm{H}=$ high microwave energy, $\mathrm{M}=$ medium microwave energy, $\mathrm{P}=$ phosphoric acid, $\mathrm{S}=$ sulphuric acid, $\mathrm{Z}=$ zinc chloride, $7,12,18=$ time of activation in minutes 
The maximum $\mathrm{MB}$ adsorption capacity of the prepared activated carbon is compared to those obtained in the literature for activated carbons prepared from various precursors and different chemical activators is as shown in
Table 4. It can be noticed that the prepared activated carbon can be considered as an effective adsorbent for removal of $\mathrm{MB}$ from aqueous solutions.

TABLE 1: FUNCTIONAL GROUPS CHARACTERIZED BY FTIR FOR PRECURSOR, AC AND AC AFTER ADSORPTION OF $\mathrm{MB}$

\begin{tabular}{|c|c|c|c|c|c|c|c|}
\hline \multirow[t]{2}{*}{ Functional Groups } & \multicolumn{2}{|c|}{ Raw Date stone } & \multicolumn{2}{|c|}{$\mathrm{AC}$} & \multicolumn{2}{|c|}{ After adsorption } & \multirow[t]{2}{*}{ Reference } \\
\hline & $\begin{array}{c}\text { Peak } \\
\text { position }\end{array}$ & intensity & $\begin{array}{c}\text { Peak } \\
\text { position }\end{array}$ & intensity & $\begin{array}{c}\text { Peak } \\
\text { position }\end{array}$ & intensity & \\
\hline Surface O-H stretching & 3431.71 & 77.9671 & 3427.85 & 78.0513 & 3426.89 & 71.2157 & Benadjemia 2011 \\
\hline Aliphatic C-H stretching & 2925.48 & 85.4814 & 2922.59 & 85.9118 & 2317.05 & 71.106 & Benadjemia 2011 \\
\hline $\begin{array}{l}\text { C-H stretching vibrations in } \\
\text { methyl and methylene groups }\end{array}$ & 2861.84 & 89.8002 & 2857.02 & 87.9686 & - & - & Benadjemia 2011 \\
\hline $\begin{array}{l}\mathrm{COOH} \text { dimmer shows an } \\
\text { intensity }\end{array}$ & 2360.44 & 101.017 & 2357.55 & 91.9957 & - & - & $\begin{array}{l}\text { Foo and Hameed } \\
2012\end{array}$ \\
\hline Carboxylate $\mathrm{C}=\mathrm{O}$ Stretching & 1740.44 & 92.6244 & - & - & - & - & Yang and Qiu 2010 \\
\hline $\begin{array}{c}\text { Carbonyl in ketone } \mathrm{C}=\mathrm{O} \\
\text { Stretching }\end{array}$ & 1640.16 & 91.7565 & 1617.98 & 81.7993 & 1586.16 & 65.3449 & Liu et al. 2010 \\
\hline $\begin{array}{c}\text { In plane bending vibration of C- } \\
\mathrm{H} \text { of methylene group and } \\
\text { methyl group }\end{array}$ & 1443.46 & 90.8962 & 1426.1 & 85.2674 & 1432.85 & 67.9518 & Yang and Qiu 2010 \\
\hline $\begin{array}{c}\text { In plane bending vibration of C- } \\
\mathrm{H} \text { of methylene group and } \\
\text { methyl group }\end{array}$ & 1378.85 & 90.3686 & - & - & 1374.03 & 66.0783 & Yang and Qiu 2010 \\
\hline $\begin{array}{l}\mathrm{C}-\mathrm{O} \text { stretching vibrations in } \\
\text { carboxylate groups }\end{array}$ & 1315.21 & 92.1104 & - & - & 1303.64 & 65.0675 & Yang and Qiu 2010 \\
\hline $\begin{array}{l}\mathrm{C}-\mathrm{O} \text { stretching vibrations in } \\
\text { alcohols, phenols, or } \\
\text { ether or ester groups }\end{array}$ & 1248.68 & 90.0477 & - & - & 1213.01 & 64.7674 & Benadjemia 2011 \\
\hline $\begin{array}{l}\text { C-O stretching in phenols, } \\
\text { alcohols }\end{array}$ & 1153.22 & 85.9001 & 1166.72 & 86.4673 & 1117.55 & 64.9897 & Liu et al. 2010 \\
\hline $\mathrm{C}-\mathrm{OH}$ stretching vibrations & 1075.12 & 83.7766 & - & - & - & - & Tan et al. 2008 \\
\hline $\begin{array}{c}\text { Out of plane OH bending in } \\
\text { carboxylic acid dimers at } 937- \\
913 \\
\end{array}$ & 942.056 & 95.0451 & - & - & - & - & Gobi et al. 2011 \\
\hline $\begin{array}{c}\mathrm{C}-\mathrm{H} \text { out of plane in -CHO } \\
\text { aldehydes }\end{array}$ & 874.56 & 97.1566 & - & - & 881.309 & 72.7947 & Benadjemia 2011 \\
\hline $\begin{array}{l}\text { Out-of-plane bending mode of } \\
\text { O-H. }\end{array}$ & 807.063 & 94.503 & - & - & 821.527 & 73.4934 & Liu et al. 2010 \\
\hline $\begin{array}{l}\mathrm{O}-\mathrm{H} \text { out-of-plane bending } \\
\text { vibrations band }\end{array}$ & 605.539 & 92.0302 & - & - & 615.181 & 76.6245 & Yang and Qiu 2010 \\
\hline
\end{tabular}


TABLE 2: ELEMENTAL ANALYSIS OF DP AND AC

\begin{tabular}{|c|c|c|c|c|c|}
\hline Material & C\% & H\% & N\% & S\% & O \% \\
\hline DP & 45.08 & 7.01 & 1.37 & Nil & 46.54 \\
\hline AC & 52.97 & 3.83 & 1.632 & Nil & 41.50 \\
\hline
\end{tabular}

TABLE 3: POROSITY CHARACTERIZATION OF DP AND AC

\begin{tabular}{|l|c|c|}
\hline & DP & AC \\
\hline $\begin{array}{l}\text { Total pore volume, } \\
\mathrm{cm}^{3} / \mathrm{g}\end{array}$ & 0.0077 & 0.0104 \\
\hline $\begin{array}{l}\text { Average pore diameter, } \\
\text { A }\end{array}$ & 14.32 & 11.46 \\
\hline BET surface area, $\mathrm{m}^{2} / \mathrm{g}$ & 21.47 & 36.51 \\
\hline
\end{tabular}

TABLE 4: ADSORPTION CAPACITIES OF DIFFERENT ACTIVATED CARBONS PREPARED BY MICROWAVE TECHNIQUE

\begin{tabular}{|c|c|c|c|}
\hline Precursor & $\begin{array}{c}\text { Chemical } \\
\text { activator }\end{array}$ & $\begin{array}{c}\text { Adsorption } \\
\text { capacity, mg/g }\end{array}$ & Reference \\
\hline $\begin{array}{c}\text { Petrochemical } \\
\text { industrial } \\
\text { waste }\end{array}$ & $\mathrm{NaOH}$ & 122.94 & $\begin{array}{c}\text { Bouchelta et al. } \\
2012\end{array}$ \\
\hline $\begin{array}{c}\text { Virgin Semi- } \\
\text { coke }\end{array}$ & $\mathrm{H}_{3} \mathrm{PO}_{4}$ & 98 & Xin et at. 2013 \\
\hline $\begin{array}{c}\text { Edible } \\
\text { fungiresidue }\end{array}$ & $\mathrm{K}_{2} \mathrm{CO}_{3}$ & 172.43 & $\begin{array}{c}\text { Xiao et al. } \\
2012\end{array}$ \\
\hline $\begin{array}{c}\text { Biodiesel solid } \\
\text { residue }\end{array}$ & - & 20.41 & $\begin{array}{c}\text { Franka and } \\
\text { Nunes 2009 }\end{array}$ \\
\hline $\begin{array}{c}\text { Waste tire } \\
\text { powder }\end{array}$ & $\mathrm{Steam}_{2}$ & 194.7 & Junior et al. \\
2013
\end{tabular}

\section{CONCLUSIONS}

Date pits were used as precursor to produce efficient and economic activated carbon via microwave irradiation. The operational variables including chemical activator, microwave power and irradiation time on the adsorption capacity of the prepared activated carbon were investigated. The activated carbon was characterized by pore structural analysis, scanning electron microscopy, FTIR and XRD. The optimum preparation conditions were identified to be high microwavepower and radiation time of 12 mins. These conditions result in $61 \mathrm{mg} / \mathrm{L}$ adsorption capacity for methylene blue. The prepared activated carbons exhibited moderate surface area and porosity. The BET surface area and total pore volume of optimum samples were $36.51 \mathrm{~m}^{2} / \mathrm{g}$ and $0.0104 \mathrm{~cm}^{3} / \mathrm{g}$, respectively. The results support the potential to prepare efficient activated carbon from dates pits by microwave assisted chemical activation.

\section{REFERENCES}

[1] Angin, D., Altintig, E., and EnnilKose, T., Influence of Process Parameters on the Surface and Chemical Properties of Activated Carbon Obtained from Biochar By Chemical Activation, Bioresource Technology, 148, 542-549, 2013.

[2] Kasim F. A., Mahdi M. A., Hasan J. J., Al-Ani S.K.J., Kasim S. J., Preparation and optical properties of CdS/Epoxy nanocomposite, Int. J. Nano electronics and Materials., 5, 57-66, 2012.

[3] Ania, C. O. , Parra, J. B., Menendez, J. A. and Pis, J. J., Effect of Microwave and Conventional Regeneration on the Microporous and Mesporous Network on the Adsorptive Capacity of Activated Carbons, Microporus and Mesoporus Materials, 63 (1-2), 7-15, 2005. 
[4] Benadjemia, M., Millière, L., Reinert, L., Benderdouche, N., and Duclaux, L., Preparation, Characterization and Methylene Blue Adsorption of Phosphoric Acid Activated Carbons from Globe Artichoke Leaves, Fuel Processing Technology, 92, 1203-1212, 2011.

[5] Bouchelta, C., Chekkat, F.A., Marsa, Z., Ramdane, N., Mechatti, F., and Medjram, M.S., Preparation of Activated Carbon from a Petrochemical Industrial Waste by $\mathrm{NaOH}$ Activation under Microwave Radiation, Application in Dyes Adsorption, Jordan Journal of Chemistry, 7 (3), 253-266, 2012.

[6] D.A. Jones, T.P. Leyveld, S.D. Mavrofidis, SW., Kingman, and Miles, N.J., Microwave Heating Applications in Environmental Engineering- A Review, Resources, Conservation and Recycling, 34 (2), 75-90, 2002.

[7] Dehdashti, A., Khavanin, A., Rezaee, A., Assilian, H., and Motalebi, M., Application of Microwave Irradiation for The Treatment of Adsorbed Volatile Organic Compounds on Granular Activated Carbon, Iran. J. Environ. Health. Sci. Eng., 8 (1), 85-94, 2011.

[8] Eletskii, P.M., Yakovlev, V.A., Fenelonov, V.B., and Parmon, V.N., Texture and Adsorptive Properties of Microporous Amorphous Carbon Materials Prepared by the Chemical Activation of Carbonized High-Ash Biomass, Kinetics and Catalysis, 49, 708-719, 2008.

[9] Feng-chin,W., Ru-ling,T., and Chi-chang, H. Comparisons of Pore Properties and Adsorption Performance of KOH-Activated and SteamActivated Carbons, Microporous and Mesoporous Materials, 80(1/3), 95-106, 2005.

[10] Foo, K.Y., and Hameed, B.H., Dynamic Adsorption Behavior Of Methylene Blue onto Oil Palm Shell Granular Activated Carbon Prepared by Microwave Heating, Chemical Engineering Journal, 203, 81-87, 2012.Raja V., Sarma A.K., Narasimha Rao V.V.R., The optical properties of pure and doped PVA-Co-P4VPNO polymer films, Materials Letters., 57, 4678-4683, 2003.

[11] Gao, Y., Yue, Q., Gao, B., Sun, Y., Wang, W., Li, Q., and Wang, Y., Comparisons of Porous, Surface Chemistry and Adsorption Properties of Carbon Derived from Enteromorphaprolifera Activated by $\mathrm{H} 4 \mathrm{P} 2 \mathrm{O} 7$ and $\mathrm{KOH}$, Chemical Engineering Journal, 232, 582-590, 2013.
[12] Gobi, K., Mashitah, M.D., and Vadivelu, V.M., Adsorptive Removal of Methylene Blue Using Novel Adsorbent from Palm Oil Mill Effluent Waste Activated Sludge: Equilibrium, Thermodynamics and Kinetic Studies, Chemical Engineering Journal, 171, 1246- 1252, 2011.

[13] Kandiyoti, R., Lazaridis, J.I., Dyrvold, B., Ravindra-Weerasinghe, C., Pyrolysis of a ZnCI2impregnated Coal in an Inert Atmosphere, Journal of Fuel, 63(11), 1583-1587, 1984.

[14] Katz , J.D., Blake, R.D. and Kenkre, V.M., Microwave Enhanced Diffusion, Ceramic Transactions Microwaves: Theory and Application in Materials Processing, American Ceramic Society, 21, 95-106, 1991.

[15] Ke-qiang, Q., Su-wen, Y., and Juan, Y., Characteristics of Activated Carbon Prepared from Chinese Fir Sawdust by Zinc Chloride Activation Under Vacuum Condition, J. Cent. South Univ. Technol., 16, 0385-0391, 2009.

[16] Khan, E.M., Doke, K.M., and Thombal, K.B., Kinetic and Isotherm Studies of Methylene Blue Removal from Aqueous Solution by Adsorption on Activated Charcoal Prepared from Wood Apple Fruit Shell, an Agricultural Waste, Der PharmaChemica, 3(1), 306-317, 2011.

[17] Lam S.S. and Chase, H.A., A Review on Waste to Energy Processes Using Microwave Pyrolysis, Energies, 5, 4209-4232, 2012.

[18] Li, W., Zhang, L., Peng, J., Li ,N., Zhu, X., Preparation of High Surface Area Activated Carbons from Tobacco Stems with $\mathrm{K}_{2} \mathrm{CO}_{3}$ Activation Using Microwave Radiation, Industrial Crops And Products, 27, 341-347, 2008.

[19] Liu, Q., Zheng, T., Wang, N., and Abulikemu, G., Modification of Bamboo-Based Activated Carbon Using Microwave Radiation and Its Effects on the Adsorption of Methylene Blue, Applied Surface Science, 256, 3309-3315, 2010.

[20] Malik, R., Ramteke, D.S., and Wate, S.R., Physico-Chemical and Surface Characterization of Adsorbent Prepared from Groundnut Shell by $\mathrm{ZnCl} 2$ Activation and its Ability to Adsorb Colour, Indian Journal of Chemical Technology, 13, 319-328, 2006.

[21] Mohd Din, A.T., Hameed, B.H. and Ahmad, A.L., Batch Adsorption of Phenol onto Physicochemical Activated Coconut Shell, 
Journal of Hazardous Materials, 161, 1522-1529, 2009.

[22] Ngiik, T.C., Adsorption of Methylene Blue By Activated Carbon Prepared from Waste Tire Powder, Thesis, Faculty of Chemical Engineering, Universiti Teknologi Malaysia, January 2013.

[23] Olivares-Marin, M., Fernandez-Gonzalez, C., Macias-Garcia, A., and Gomez-Serrano, V., Preparation of Activated Carbon from Cherry Stones by Chemical Activation with Potassium Hydroxide, Journal of Applied Surface Science, 252(17), 5980-5983, 2006.

[24] Pezoti, O., Cazetta, A.L., Gomes, R.C., Barizão, E.O., Souza, I., Martins, A.C., Asefa, T., and Almeida, V.C., Synthesis of $\mathrm{ZnCl}$-activated Carbon from Macadamia Nut Endocarp (Macadamia integrifolia) by Microwave-Assisted Pyrolysis: Optimization Using RSM and Methylene Blue Adsorption, Journal of Analytical and Applied Pyrolysis, 105, 166-176, 2013.

[25] Shen, W., Li, Z., and Liu, Y., Surface Chemical Functional Groups Modification of Porous Carbon, Recent Patents on Chemical Engineering, 1, 27-40, 2008.

[26] Sutton W.H., Microwave Processing of Ceramic Materials, American Ceramic Society Bulletin, 68 (2), 376-386, 1989.

[27] Tan, I.A.W., Ahmad, A.L., and Hameed, B.H., Enhancement of Basic Dye Adsorption Uptake from Aqueous Solutions Using Chemically Modified Oil Palm Shell Activated Carbon, Colloids and Surfaces A: Physicochem. Eng. Aspects, 318, 88-96, 2008.

[28] Thomas, J.R., Katz, K.D. and Blake, R.D., Temperature Distribution in Microwave Sintering of Alumina Cylinders, Microwave Processing of Materials IV, Materials Research Society Symposium Proceedings. Materials Research Society, 347, 311-316, 1994.

[29] Thostenson E.T. and Chou T.W., Microwave processing: fundamentals and applications, Composites Part A: Applied Science and Manufacturing, 30 (9), 1055-1071, 1999.
[30] Valente Nabais, J.M., Carrott, P.J.M., RibeiroCarrott, M.M.L., and Men_endez, J.A., Preparation and Modification of Activated Carbon Fibres by Microwave Heating, Carbon, 42, 1315-1320, 2004.

[31] Viboon, S., Chiravoot, P., Duangdao, A., and Duangduen, A., Preparation and Characterization of Activated Carbon from the Pyrolysis of Physic Nut (Jatrophacurcas L.) Waste, Energy Fuels, 22 (1), 31-37, 2008.

[32] Xiao, H., Peng, H., Deng, S., Yang, X., Zhang, Y., and Li, Y., Preparation of Activated Carbon From Edible Fungi Residue by Microwave Assisted $\mathrm{K}_{2} \mathrm{CO}_{3}$ Activation Application in Reactive Black 5 Adsorption from Aqueous Solution, Bioresource Technology, 111, 127-133, 2012.

[33] Xin, W., Jin-hui, P., and Xin-hui , D., Preparation of Modified Semi-Coke by Microwave Heating and Adsorption Kinetics of Methylene Blue, Journal of Microwave Power and Electromagnetic Energy, 47 (2), 110-125, 2013.

[34] Yang, J., and Qiu, K., Preparation of Activated Carbons from Walnut Shells Via Vacuum Chemical Activation and Their Application for Methylene Blue Removal, Chemical Engineering Journal, 165, 209-217, 2010.

[35] Yuen, F.K., and Hameed, B.H., Recent Developments in The Preparation and Regeneration of Activated Carbons by Microwaves, Adv. Colloid Interface Sci., 149, 19-27, 2009.

[36] Cansado, I. P.P., Mourão, P.A.M., Carrott, P.J.M. and RibeiroCarrott, M.M.L., Direct Nitrogen Enrichment of Activated Carbon Produced from Synthetic or Natural Precursor, QUI - Artigosem Livros de Actas/Proceedings, 12-14 September, 2012. 


\section{إعداد وتوصيف الكربون المنشط من المخلفات الزراعية عن طريق أشعة الميكروويف}

$$
\begin{aligned}
& \text { 1,2 حسام الطاهر، } 3 \text { منار حسن، } 1 \text { فهد العوفي ، } 4 \text { يحي مجدي } \\
& 1 \text { قسم تكنولو جيا الهندسة الكيميائية ـ كلية ينبع الصناعية ـ المملكة العربية السعودية } \\
& 2 \text { قسم الهندسة الكيميائية ـ كلية الهندة - جامعة نزوى - سلطنة عمان } \\
& 3 \text { المعهد القومى لليزر - القاهرة - مصر } \\
& 4 \text { قسم الهندسة الكيميائية - كلية الهندسة - جامعة المنيا - مصر }
\end{aligned}
$$

الملخص:

في هذه الدراسة، ومن خلال أثنعة الميكروويف تم إعداد الكربون المنشط من نوى التمر بإستخدام ثلاثة منشطات كيميائية هم كلوريد الزنك وحامض الفوسفوريك وحامض الكبريتيك. وتم تقييم ظروف التحضير الختلفة مثل نوع المنشط، وطاقة التنشيط ووقت التنشيط بواسطة أثعة الميكروويف. كما تم تقييم كفاءة الأداء للكربون المنشط عن طريق إمنصاص صبغة أزرق الميثيلين. كما تم دراسة خصائص الكربون المنشط بو اسطة المجهر الإكتروني الماسح و الأشعة تحت الحمر اءو الأشعة السينية، كما تم تحليل توزيع المسام و تحديد مساحة سطح الكربون المنشط المنتج. إستناداً للنتائج فان الظروف المثلى لإعداد الكربون المنثط كانت 12 دقيقة كزمن للحرق بو اسطة فرن الميكروويف مع إستخدام الطاقة القصوى و إستخدام كلوريد الزنك كمنشط كيميائى. في ظل هذه الظروف تصل قدرة إمتصاص صبغة أزرق الميثلين الى 61 ملجم/جرام. وقد عززت عملية التشيط إلى حد كبير سطح نوى التمر من خلال زيادة المسامية و كذلك زيادة مساحة سطحه. 